\title{
Pengaruh Pendidikan Kesehatan terhadap Kecemasan tentang Menarche pada Siswi Kelas V Sekolah Dasar
}

\author{
Anggi Winarti ${ }^{1}$, Fatma Siti Fatimah ${ }^{1}$, Wahyu Rizky ${ }^{1}$ \\ ${ }^{1}$ Prodi Ners Universitas Alma Ata Yogyakarta \\ Jalan Ringroad Barat Daya Tamantirto, Kasihan, Bantul, Yogyakarta \\ Email: fatmasitifatimah@gmail.com
}

\begin{abstract}
Abstrak
Menarche merupakan bagian dari perubahan primer yang biasa memengaruhi efek psikologis pada anak. Dampak psikologis dari menarche dapat berupa kecemasan yang akan menimbulkan banyak masalah pada anak. Berdasarkan penelitian Randomination Study of Childhood BMI and Early Menarche memperoleh hasil anak perempuan yang mengalami menarche pertama mengalami perubahan pada dirinya baik secara psikis seperti timbul rasa cemas maupun terjadi perubahan seperti obesitas. Kecemasan merupakan gejala yang paling sering terjadi pada anak dan sangat mencolok pada peristiwa menarche yang diperkuat adanya keinginan menolak proses fisiologis tersebut. Kecemasan dapat dipengaruhi oleh faktor umur, genetik, tingkat pengetahuan dan lain-lain. Pemberian informasi tentang menstruasi melalui pendidikan kesehatan merupakan salah satu cara untuk mengatasi gejala-gejala gangguan psikologis yang muncul saat menghadapi menarche. Tujuan penelitian untuk mengetahui pengaruh pendidikan kesehatan terhadap kecemasan tentang menarche pada siswi kelas V di SDN Sonosewu dan SD Muhammadiyah Ambarbinangun Kasihan Bantul Yogyakarta. Penelitian ini menggunakan quasi ekspriment dengan control time series design atau the eqievalent material sample design. Sampel dalam penelitian ini adalah siswi kelas V di SDN Sonosewu sebanyak 15 siswi dan SD Muhammadiyah Ambarbinangun 15 siswi yang belum menstruasi dengan menggunakan teknik total sampling. Data dikumpulkan dengan menggunakan kuesioner dan dianalisis dengan menggunakan uji wilcoxon. Hasil penelitian ini nilai p-value 0,023 kelompok intervensi dan p-value 0,234 kelompok kontrol $(<0,05)$. Hasil uji statistik menunjukkan terdapat perbedaan yang signifikan pada kelompok intervensi. Kesimpulan terdapat perbedaan yang signifikan antara sebelum dan sesudah diberikan pendidikan kesehatan dalam menghadapi menarche.
\end{abstract}

Kata kunci: menarche, pendidikan kesehatan, kecemasan

\section{Influence of Health Education Toward The Anxiety about Menarche in $5^{\text {th }}$ grade Students of Elementary School}

\begin{abstract}
Menarche is part of the primary change that commonly affects the psychology of a child. The psychological impact of menarche can be in a form of anxiety which lead to many problems to children. Based on research Randomination of childhood BMI and Early Menarche gained the results of girls who experience her first menarche changes in her either psychic like arise a sense of anxiety and happened changes such obesity. Anxiety is the most common, noticeable symptom in children during menarche and it is sometimes reinforced the desire to reject the physiological process. Anxiety can be influenced by age, genetics, level of knowledge and others. Provision of information about menstrual health through education is one way to deal with the symptoms of psychological disorders that arise when facing menarche. Objective: to determine the effect of health education of anxiety in menarche in students at $5^{\text {th }}$ grade Sonosewu Elementary School and Muhammadiyah Ambarbinangun Elementary School. This study uses quasi experiment research to control time series design or the sample material eqievalent design. The sample in this study is at $5^{\text {th }}$ grade students in Sonosewu Elementary School 15 and Muhammadiyah Ambarbinangun Elementary School 15 who are not having menstruation yet, in total of 30 students, taken using total sampling technique. Data were collected using a questionnaire and analyzed using the Wilcoxon test. Results showed that p-value 0.023
\end{abstract}


experimental group and p-value 0.234 the control group (<0.05). And from statistical test, the result showed that the differentiation was meaningful on intervention group. In conclusion, there was a significant influence of health education toward the anxiety about menarche in $5^{\text {th }}$ grade students.

Keywords: menarche, health education, anxiety

Info Artikel:

Artikel dikirim pada 17 November 2016

Artikel diterima pada 08 Maret 2017

DOI : http://dx.doi.org/10.21927/jnki.2017.5(1).51-57

\section{PENDAHULUAN}

Masa peralihan antara masa kanak-kanak dan masa remaja merupakan masa pubertas. Pubertas adalah proses kematangan dan pertumbuhan yang terjadi ketika organ-organ reproduksi mulai berfungsi dan karakteristik seks sekunder mulai muncul (1). Kejadian penting pada masa pubertas adalah masa ketika seorang anak mengalami perubahan fisik dan psikis (2). Menurut Proverawati menarche adalah menstruasi yang pertama kali, yaitu keluarnya darah dari alat kelamin wanita atau luruhnya lapisan dinding dalam rahim yang banyak mengandung pembuluh darah, secara normal menstruasi awal terjadi pada usia 11-16 tahun (3).

Berdasarkan hasil penelitian Rosidah yang menunjukkan hasil $28,9 \%$ siswa mempunyai pengetahuan yang baik tentang menstruasi, $26,9 \%$ berpengetahuan cukup dan 44,2\% mempunyai pengetahuan kurang. Kurangnya pengetahuan remaja disebabkan karena dari segi fisik dan psikologis remaja belum matang, informasi yang kurang dari orang tua, dan sulitnya mencari informasi karena tempat tinggal yang jauh dari perkotaan (4).

Menarche merupakan peristiwa penting pada remaja sebagai tanda kematangan seksual telah dimulai. Datangnya menarche justru membuat sebagian remaja putri merasa bingung, gelisah, tidak nyaman bahkan menganggap bahwa menarche adalah suatu penyakit, hal ini timbul karena mereka belum tahu tentang menarche maupun penatalaksanaanya. Kesiapan mental sangat diperlukan sebelum menarche karena perasaan cemas dan takut akan muncul. Kecemasan adalah sinyal yang menyadarkan seseorang untuk memperingatkan adanya bahaya yang mengancam (5). Menurut Ramathuba sebanyak $73 \%$ responden mengalami ketakutan dan kecemasan, sehingga dibutuhkan intervensi untuk meningkatkan peluang mereka untuk mendiskusikan tentang menstruasi dan akses informasi dari orang dewasa khususnya ibu (6).

Kurangnya pengetahuan tentang kesehatan reproduksi khususnya menstruasi pada remaja putri disebabkan oleh beberapa faktor diantaranya tidak adanya informasi dari orangtua, teman sebaya, guru, kakak atau saudara perempuan. Menurut Notoatmodjo orangtua sering tidak tahu tentang informasi apa yang harus diberikan kepada anak menjelang akil baligh (7). Penelitian Fajri dan Khairani menunjukkan sebagian besar subjek menjalin komunikasi yang cukup efektif dengan ibunya yaitu dalan kategori sedang, sebagian besar subjek cukup siap dalam menghadapi menstruasi pertama (menarche) (8). Didukung Aboyeji, ibu mempunyai peran yang besar dalam memberikan informasi tentang menstruasi kepada anak. Oleh karena itu, ibu diharapkan dapat memberikan dukungan emosi sehingga anak merasa nyaman dan tidak takut ketika mengalami menarche. Pengetahuan yang dapat diberikan kepada remaja tentang menarche dapat berupa pengetahuan tentang proses terjadinya menstruasi secara biologis, kebersihan pada saat menstruasi, dukungan emosional dan dukungan psikologis (9). Sedangkan orangtua yang tidak tahu tentang informasi apa yang harus diberikan kepada anak, keadaan ini yang dapat menyebabkan anak tidak siap dalam menerima datangnya menarche. Dampak dari ketidaksiapan dalam menghadapi menarche pada remaja putri dapat menimbulkan kecemasan, menimbulkan gejala-gejala patologis seperti rasa takut, kepala pusing, disminorhea, pegalpegal di kaki dan di punggung (3).

Informasi tentang menarche sebenarnya adalah kewajiban orangtua, namun kebanyakan orangtua menganggap hal ini tabu dan orangtua juga kesulitan untuk menyampaikan informasi karena keterbatasan pengetahuan. Informasi dari orangtua maupun guru di sekolah sangat diperlukan bagi seorang anak untuk mengurangi kecemasan dalam menghadapi 
perubahan-perubahan yang terjadi pada masa remaja (10). Menurut Kalman, ketika seorang remaja perempuan mengalami menarche mereka akan mencari informasi tentang menstruasi dari ibu mereka (11). Penelitian Fajri dan Khairani menyatakan bahwa komunikasi ibu anak memiliki hubungan positif dengan kesiapan menghadapi menstruasi pertama, semakin bagus komunikasi yang dilakukan oleh orang tua dan informasi yang diberikan oleh terutama ibu maka anak akan lebih siap dalam menghadapi menarche (8).

Informasi tidak hanya bisa diperoleh dari orang tua namun informasi juga bisa didapat melalui petugas kesehatan salah satunya dengan pendidikan kesehatan (7). Sekolah perlu mendapatkan perhatian semua pihak. Sekolah merupakan langkah yang strategis untuk meningkatkan kesehatan masyarakat khususnya anak anak karena sekolah merupakan lembaga yang didirikan untuk membina dan meningkatkan sumber daya manusia baik fisik, mental, moral maupun intelektual. Pendidikan kesehatan melalui sekolah paling efektif diantara usaha kesehatan masyarakat yang lain khususnya peran tenaga kesehatan dalam memberikan pendidikan kesehatan (7).

Tujuan penelitian ini untuk mengetahui tentang pengaruh pendidikan kesehatan terhadap tingkat kecemasan tentang menarche pada siswi kelas $V$ di SDN Sonosewu dan SD Muhammadiyah Ambarbinangun.

\section{BAHAN DAN METODE}

Jenis penelitian ini merupakan penelitian quasi eksperiment dengan rancangan control time series design (rancangan rangkaian waktu dengan kelompok pembanding). Penelitian ini dilaksanakan pada 25 Februari sampai 4 Maret 2016. Populasi dalam penelitian ini adalah Siswi-siswi kelas $V$ di SDN Sonosewu sebanyak 15 siswi dan SD Muhammadiyah Ambarbinangun sebanyak 15 siswi sehingga jumlah keseluruhan yang memenuhi kriteria sebanyak 30 siswi. Pengambilan sampel menggunakan teknik total sampling. Variabel bebas adalah pendidikan kesehatan dan variabel terikat adalah kecemasan terhadap menarche. Pendidikan kesehatan diberikan dengan metode ceramah yang menggunakan media flif chart dan leaflet. Instrumen yang digunakan dalam penelitian ini adalah kuesioner menggunakan skala ordinal, yaitu tidak cemas: $<40 \%$, cemas ringan: 40-65\%, cemas sedang: $66-85 \%$ dan cemas berat: $86-100 \%$. Uji validitas menggunakan rumus Pearson
Product Moment yang di adopsi dari penelitian Ratna Dwi Astriani dengan judul hubungan pengetahuan tentang menstruasi dengan tingkat kecemasan mengahadapi menarche pada Siswi Kelas 1 di SMP PGRI Kasihan Bantul (12). Kuesioner tingkat kecemasan pertanyaan yanng tidak valid sebanyak 8 soal yaitu nomor 4, 5, 6, 12, 16, 27, 28 dan 30 . Jadi kuesioner tingkat kecemasan dari 30 butir soal yang dinyatakan valid terdapat 22 butir soal dan uji reliabilitas dilakukan dengan rumus KR-20, di dapatkan besar koefesien KR-20 adalah 0,919 dan $p$ sebesar 0,000 . Maka $r$ hitung $>r$ tabel dan $p<0,05$, jadi kuesioner tingkat kecemasan ini valid untuk digunakan dalam penelitian (12). Sedangkan analisis data yang dilakukan menggunakan analisis univariat dan bivariat. Uji univariat bertujuan untuk mengetahui gambaran karakteristik dari responden dalam bentuk frekuensi dan persentase. Analisis bivariat merupakan analisis yang dilakukan untuk mengetahui perbedaan pretest dan posttest pada kedua kelompok yaitu menggunakan uji Wilcoxon (13).

\section{HASIL DAN BAHASAN}

\section{Kecemasan Sebelum Intervensi}

Berikut adalah tabel yang menunjukkan kategori kecemasan digolongkan menjadi kecemasan tidak cemas, cemas ringan, cemas sedang dan cemas berat pada saat sebelum diberikan intervensi pada kedua kelompok.

Tabel 1. Kecemasan Sebelum Diberikan Intervensi pada Kelompok Intervensi dan Kelompok Kontrol Siswi Kelas V di SDN Sonosewu Kasihan Bantul Yogyakarta

\begin{tabular}{lcccc}
\hline \multirow{2}{*}{ Variabel } & \multicolumn{2}{c}{$\begin{array}{c}\text { Kelompok } \\
\text { Intervensi }\end{array}$} & \multicolumn{2}{c}{$\begin{array}{c}\text { Kelompok } \\
\text { Kontrol }\end{array}$} \\
\cline { 2 - 5 } & $\mathbf{f}$ & $\%$ & $\mathbf{f}$ & $\%$ \\
\hline Tidak cemas & 1 & 6,7 & 5 & 33,3 \\
Cemas ringan & 3 & 2,00 & 5 & 33,3 \\
Cemas sedang & 5 & 33,3 & 5 & 33,3 \\
Cemas berat & 6 & 40,0 & 0 & 0 \\
$\quad$ Jumlah & 15 & 100,0 & 15 & 100,0 \\
\hline
\end{tabular}

Sumber: Data Primer Tahun 2016

Berdasarkan Tabel 1 menunjukkan bahwa kecemasan tentang menarche sebelum intervensi terdapat 6 orang $(40,0 \%)$ dengan cemas berat dan 1 orang $(6,7 \%)$ tidak cemas. Sedangkan pada kelompok kontrol terdapat 5 orang $(33,3 \%)$ dengan cemas sedang dan 5 orang $(33,3 \%)$ tidak cemas. 
Perasaan cemas jika tidak segera ditanggulangi akan menjadi masalah yang serius pada anak. Hal ini dipengaruhi oleh berbagai faktor, antara lain pengalaman masa kecil yang bernilai emosi tinggi, sehingga pada masa berikutnya dapat menimbulkan kecemasan (14). Hasil penelitian pada kelompok pre-test menujukkan mayoritas siswi belum mendapatkan informasi mengenai menarche. Hal tersebut didukung dari hasil studi pendahuluan bahwa informasi siswi tentang menarche masih kurang karena ada beberapa faktor diantaranya kurangnya informasi dari orang tua, kakak, saudara perempuan, teman sebaya maupun guru atau pendidikan yang didapat siswi. Keadaan ini dapat menyebabkan anak tidak siap menerima datangnya menarche. Dampak lanjut ketidaksiapan menghadapi menarche pada remaja putri dapat menimbulkan kecemasan, gejalagejala patalogis seperti rasa takut, konflik batin, dan gangguan lainnya yaitu berupa pusing, mual, disminorhea dan menstruasi tidak teratur (3).

\section{Kecemasan Sesudah Intervensi}

Kategori kecemasan digolongkan menjadi kecemasan tidak cemas, cemas ringan, cemas sedang dan cemas berat. Pengukuran kedua pada kelompok kontrol dan pengukuran kedua setelah intervensi pendidikan kesehatan pada kelompok intervensi disajikan pada Tabel 2.

Tabel 2. Kecemasan Sesudah Diberikan Intervensi pada Kelompok Intervensi dan Kelompok Kontrol Siswi Kelas V di SDN Sonosewu Kasihan Bantul Yogyakarta

\begin{tabular}{lcccc}
\hline \multirow{2}{*}{ Variabel } & \multicolumn{2}{c}{$\begin{array}{c}\text { Kelompok } \\
\text { Intervensi }\end{array}$} & \multicolumn{2}{c}{$\begin{array}{c}\text { Kelompok } \\
\text { Kontrol }\end{array}$} \\
\cline { 2 - 5 } & $\mathbf{f}$ & $\mathbf{\%}$ & $\mathbf{f}$ & $\%$ \\
\hline Tidak Cemas & 3 & 20,0 & 7 & 46,7 \\
Cemas Ringan & 3 & 20,0 & 5 & 33,3 \\
Cemas Sedang & 7 & 46,7 & 3 & 2,00 \\
Cemas Berat & 2 & 13,3 & 0 & 0 \\
$\quad$ Jumlah & 15 & 100,0 & 15 & 100,0 \\
\hline
\end{tabular}

Sumber: Data Primer Tahun 2016

Bersadarkan Tabel 2 menunjukkan bahwa pada kelompok intervensi kecemasan tentang menarche setelah intervensi terdapat 2 orang $(13,3 \%)$ dengan cemas berat dan 3 orang $(20,0 \%)$ tidak cemas. Berbeda dengan kelompok kontrol yang menjadi 3 orang $(2,00 \%)$ dengan cemas sedang dan 7 orang $(46,7 \%)$ tidak cemas.
Kategori kecemasan berdasarkan kedua kelompok yang dilihat pada saat pretest dan posttest disajikan dalam Tabel 3.

Tabel 3. Kecemasan Sebelum dan Sesudah Diberikan Intervensi pada Kelompok Intervensi dan Kelompok Kontrol

\begin{tabular}{lcccc}
\hline \multirow{2}{*}{ Variabel } & \multicolumn{2}{c}{$\begin{array}{c}\text { Kelompok } \\
\text { Intervensi }\end{array}$} & \multicolumn{2}{c}{ Kelompok Kontrol } \\
\cline { 2 - 5 } & Pretest & Posttest & Pretest & Posttest \\
\hline Tidak Cemas & 1 & 3 & 5 & 7 \\
Cemas Ringan & 3 & 3 & 5 & 5 \\
Cemas Sedang & 5 & 7 & 5 & 3 \\
Cemas Berat & 6 & 2 & 0 & 0 \\
\multicolumn{1}{c}{ Jumlah } & 15 & 15 & 15 & 15 \\
\hline
\end{tabular}

Sumber: Data Primer Tahun 2016

Tabel 3 menunjukkan pada kelompok intervensi setelah diberikan pendidikan kesehatan maka tingkat kecemasan menurun dilihat dari nilai pretest dalam kategori cemas berat 6 responden setelah posttest menjadi 2 responden menurun sebanyak 4 responden. Hasil penelitian ini sesuai dengan penelitian Ummul yang menunjukkan bahwa sebagian besar siswi mengalami cemas dalam kategori berat dan sedang saat mengahadapi menarche sebelum dilakukan penyuluhan kesehatan tentang menstruasi (15). Hasil dari penelitian ini menunjukkan bahwa hasil posttest lebih baik dari hasil pre-test, hal ini disebabkan adanya suatu perlakuan berupa pemberian intervensi pendidikan kesehatan tentang menarche pada siswi kelas V di SDN Sonosewu.

\section{Perbedaan Sebelum dan Sesudah Diberikan Pendidikan Kesehatan}

Perbedaan kecemasan sebelum dan sesudah diberikan intervensi pada kelompok intervensi dan kelompok kontrol yang dilakukan analisis statistik menggunakan Wilcoxon test disajikan dalam Tabel 4.

Hasil uji Wilcoxon Signed Rank pada Tabel 4 menunjukkan bahwa variabel kecemasan pada kelompok intervensi antara pre-test dan post-test mempunyai nilai signifikan 0,023 yang lebih kecil dari nilai alpha 0,05 . Sehingga dapat disimpulkan bahwa ada perbedaan yang signifikan pada variabel kecemasan antara sebelum dan sesudah pemberian pendidikan kesehatan pada kelompok intervensi. Berbeda dengan kelompok kontrol antara pre-test dan pos-test mempunyai nilai 0,234 yang lebih besar dari nilai 0,05 , sehingga dapat disimpulkan bahwa tidak ada perbedaan 
Tabel 4. Perbedaan Kecemasan Sebelum dan

Sesudah Diberikan Intervensi pada Kelompok Intervensi dan Kelompok Kontrol Siswi Kelas V di SDN Sonosewu Kasihan Bantul Yogyakarta Bulan Februari-Maret 2016

\begin{tabular}{lccccc}
\hline \multirow{2}{*}{ Kelompok } & \multicolumn{2}{c}{ Sebelum } & \multicolumn{2}{c}{ Sesudah } & \multirow{2}{*}{ p-value } \\
\cline { 2 - 5 } & $\mathbf{n}$ & $\%$ & $\mathbf{n}$ & $\%$ & \\
\hline \multirow{3}{*}{ Intervensi } & 1 & 6,7 & 3 & 20,0 & \\
& 3 & 20,0 & 3 & 20,0 & \multirow{2}{*}{023} \\
& 5 & 33,3 & 7 & 46,7 & \\
\hline \multirow{3}{*}{ Kontrol } & 6 & 40,0 & 2 & 13,3 & \\
& 5 & 33,3 & 7 & 46,7 & \\
& 5 & 33,3 & 5 & 33,3 &, 234 \\
\hline
\end{tabular}

Sumber: Data Primer Tahun 2016

tingkat kecemasan yang signifikan pada variabel kecemasan kelompok kontrol.

Kelompok kontrol meskipun dalam kategori sedang pada saat pretest 5 dan posttest menjadi 3 namun penurunannya hanya 2 responden dan bisa jadi dikarenakan berbagai faktor, meskipun menurun tapi penurunan ini tidak bermakna dapat dilihat di Tabel 4. Hal ini sesuai dengan hasil penelitian yang dilakukan Grhasta bahwa rata-rata hasil skor posttest tidak berbeda jauh dengan rata-rata hasil skor pre-test, hal ini menunjukkan tidak terjadi penurunan tingkat kecemasan yang signifikan pada kelompok kontrol (16). Adanya perbedaan skor kecemasan pada responden setelah diberikan pendidikan kesehatan disebabkan oleh banyak faktor, diantaranya: faktor materi, pengetahuan, dukungan sosial, kondisi individual dan subjek belajar.

Keadaan cemas yang berlangsung terus menerus dapatmenyebabkan anak tidaksiap menerima datangnya menarche. Dampak lanjut ketidaksiapan menghadapi menarche pada remaja putri dapat menimbulkan kecemasan, gejala-gejala patalogis seperti rasa takut, konflik batin, dan gangguan lainnya yaitu berupa pusing, mual, disminorhea dan menstruasi tidak teratur. Hawari juga menyatakan bahwa kecemasan merupakan gangguan dalam perasaan yang ditandai dengan perasaan ketakutan dan kekhawatiran yang mendalam dan berkelanjutan, tidak mengalami gangguan dalam menilai realitas, perliku dapat terganggu tetapi masih dalam batas normal. Salah satu cara untuk mengurangi kecemasan adalah dengan meningkatkan pengetahuan melalui pemberian pendidikan kesehatan tentang mentruasi (17).

Hasil penelitian pada Tabel 4 didapatkan bahwa ada perbedaan sebelum dan sesudah di berikan pendidikan kesehatan terhadap kecemasan didapatkan hasil yang signifikan $(p=0,023)$. Hasil dari penelitian ini menunjukkan bahwa hasil posttest lebih baik dari hasil pre-test, hal ini disebabkan adanya suatu perlakuan berupa pemberian intervensi pendidikan kesehatan. Sedangkan pada kelompok kontrol di dapatkan nilai $(p=0,234)$ dapat disimpulkan bahwa tidak ada perbedaan yang signifikan karena kelompok kontrol tidak diberikan intervensi. Hasil penelitian ini juga dapat menjadi salah satu preventif untuk mengatasi dampak ketidaksiapan anak dalam menghadapi menarche.

Keberhasilan dalam peningkatan pengetahuan dalam penelitian ini karena pendidikan kesehatan yang dilakukan didukung dengan materi yang merupakan kebutuhan dari responden, selain itu metode flip chart (lembar balik) dan tanya jawab selama pendidikan kesehatan berlangsung dapat mengembangkan komunikasi antara pemateri dan sasaran. Faktor lainnya yaitu pengetahuan karena pada dasarnya pengetahuan meliputi tahu, paham, penerapan, analisa, sintesa dan evaluasi. Memberikan pengertian tentang tingkat kemampuan tahu yaitu kemampuan responden untuk menghafal, mengingat, mendefinisi, mengenali atau mengidentifikasi informasi tentang fakta, peraturan, prinsip, kondisi dan syarat yang disajikan dalam pengajaran. Selain materi dan pengetahuan faktor yang mempengaruhi kecemasan lainnya dapat berupa dukungan sosial seperti keluarga, dalam keluarga biasanya terjalin dalam bentuk komunikasi antara anak dan anggota keluarga lainnya. Ibu mempunyai peran yang besar dalam memberikan informasi tentang menstruasi kepada anak. Ketika remaja merasa tidak nyaman dan takut pada saat mengalami menarche seorang ibu diharapkan dapat memberikan dukungan emosi (18).

Hasil penelitian dengan memberikan intervensi berupa pemberian pendidikan kesehatan tentang menarche lebih dini terutama usia sekolah dasar dapat merubah pengetahuan dan mengetahui bagaimana cara mencegah hal-hal yang merugikan kesehatan yang berdampak terhadap timbulnya masalah psikologis seperti takut dan cemas. Hasil penelitian ini sama dengan penelitian yang dilakukan oleh Widyarini yang mengatakan penyuluhan tentang menarche efektif untuk menurunkan tingkat kecemasan siswi dalam mengahadapi menarche (19).

Penelitian Isnaini senada dengan menyebutkan, ada perbedaan yang bermakna antara pemberian 
pendidikan kesehatan terhadap penurunan kecemasan menghadapi menarche pada siswi kelas 5 dan 6 SD Negri Ngoto Bantul(20). Hal ini diperkuat oleh hasil penelitian Yulia dengan judul hubungan pengetahuan dengan tingkat kecemasan siswi dalam menghadapi menarche di SD Negeri 03 Alai Padang yang menyatakan bahwa ada hubungan yang signifikan antara pengetahuan dengan tingkat kecemasan menghadapi menarche (21).

Hasil penelitian ini baru menganalisis perbedaan sebelum dan sesudah dilakukan pendidikan kesehatan pada setiap kelompok, tetapi belum dilakukan analisis perbedaan pada kedua kelompok untuk membandingkan efektifitas pendidikan kesehatan pada kedua kelompok.

\section{SIMPULAN DAN SARAN}

Berdasarkan hasil dan bahasan dapat disimpulkan bahwa kecemasan pada kelompok intervensi sebelum diberikan pendidikan kesehatan terdapat 6 orang $(40,0 \%)$ dengan cemas berat dan 1 orang $(6,7 \%)$ tidak cemas. Sedangkan pada kelompok kontrol terdapat 5 orang $(33,3 \%)$ dengan cemas sedang dan 5 orang $(33,3 \%)$ tidak cemas. Kecemasan pada kelompok intervensi sesudah diberikan pendidikan kesehatan terdapat 2 orang $(13,3 \%)$ dengan cemas berat dan 3 orang $(20,0 \%)$ tidak cemas. Sedangkan pada kelompok kontrol terdapat 3 orang $(2,00 \%)$ dengan cemas sedang dan 7 orang $(46,7 \%)$ tidak cemas. Terdapat perbedaan yang signifikan pada kelompok intervensi antara sebelum dan sesudah diberikan pendidikan kesehatan dengan nilai $p=0,023$. Berbeda dengan kelompok kontrol mempunyai nilai 0,234 dapat disimpulkan bahwa tidak ada perbedaan yang signifikan.

Bagi SDN Sonosewu dan SD Muhammadiyah Ambarbinangun diharapkan sekolah memasukkan program pengajaran yang membahas materi khusus tentang kesehatan reproduksi dan siswi hendaknya lebih aktif mencari informasi tentang menarche ataupun kesehatan reproduksi sehingga dapat merawat atau menjaga kesehatan dalam kehidupan sehari-hari. Diharapkan penelitian ini dapat menambah ilmu pengetahuan, wawasan serta pengalaman dan dapat mengaplikasikan ilmu yang dimiliki langsung dilapangan nanti dan penelitian ini dapat diteliti lagi dengan menambahkan faktor-faktor yang mempengaruhi kecemasan tentang menarche.

\section{RUJUKAN}

1. Wong LD. Buku Ajar Keperawatan Pediatrik. 6th ed. Jakarta: EGC; 2009.

2. Ali M. Psikologi Remaja. Jakarta: Bumi Aksara; 2009.

3. Proverawati A, Misaroh. Menarche dan Menstruasi Penuh Makna. Yogyakarta: Nuha Medika; 2009.

4. Rosidah I. Gambaran Pengetahuan Remaja tentang Menstruasi Pertama (menarche) pada Siswi SMP Harapan Desa Paya Bakung Kecamatan Hamparan Perak Tahun 2006. Institut Kesehatan Helvetia; 2006.

5. Ibrahim, Ayubsani H. Panik Neurosis dan Gangguan Cemas. Tangerang: Jelajah Nusa; 2012.

6. Ramathuba DU. Menstrual Knowledge and Practices of Female Adolescents in Vhembe district, Limpopo Province, South Africa. Curationis [Internet]. 2015 Nov 26;38(1). Available from: http://www.ncbi.nlm. nih.gov/pubmed/26841923.

7. Notoatmodjo S. Promosi Kesehatan Teori dan Aplikasi. Jakarta: Rineka Cipta; 2007.

8. Fajri A, Khairani M. Hubungan antara Komunikasi Ibu-Anak dengan Kesiapan Menghadapi Menstruasi Pertama (Menarche) Pada Siswi SMP Muhammadiyah Banda Aceh. J Psikol Undip. 2011;10(2).

9. Aboyeji, Saidu, Abiodun, Fawole, Adewara, Adegoke. Menstrual Preparation Among Adolescents in Kwarta State. University of Ilorin Teaching Hospital; 2005.

10. Ninawati, Kuryadi J. Hubungan antara Sikap Terhadap Menstruasi dan Kecemasan Terhadap Menarche. J Psikol. 2006;4(1).

11. Kalman M. Taking a different Path: Menstrual Preparation for Adolescent Girls Living Apart From Their Mothers. Health Care Women Int [Internet]. 2003 Dec;24(10):868-79. Available from: http:// www.ncbi.nlm.nih.gov/pubmed/14742126.

12. Astriani RD. Hubungan Pengetahuan tentang Menstruasi dengan Tingkat Kecemasan Mengahadapi menarche pada Siswi Kelas $1 \mathrm{Di}$ SMP PGRI Kasihan Bantul. STIKES Alma Ata Yogyakarta; 2009.

13. HidayatA. Pengolahan dan Analisis Data Kesehatan. Cimahi: Pustaka Tarbiyah Baru; 2008.

14. Wawan. Teori dan Pengukuran Pengetahuan Sikap dan Perilaku Manusia. Yogyakarta: Nuha Medika; 2010. 
15. Ummul MI. Perbedaan Tingkat Kecemsan terhadap Menarche Sebelum dan Sesudah diberikan Penyuluhan tentang Menstruasi pada Siswi Kelas 5 dan 6 SD Negri Ngoto Bantul. STIKES Alma Ata Yogyakarta; 2012.

16. Perestroika GD, Agustin RW, Budi E. Pengaruh Penyuluhan Menstruasi Terhadap Kecemasan Menghadapi Menarche pada Remaja Putri Kelas VII SMPN 2 Punggelan Banjarnegara. J Kebidanan [Internet]. 2014;3(1). Available from: http://jurnal.unimus.ac.id/index.php/jur_bid/ article/view/1081.

17. Hawari D. Manajemen Stress, Cemas dan Depresi. Jakarta: Fakultas Kedokteran Universitas Indonesia; 2001.

18. Sumanto R. Hubungan Tingkat Nyeri Dengan Tingkat Kecemasan pada Pasien Post Operasi
SC Di RSU PKU Muhamamdiyah Gombong. STIKES Muhammadiyah Gombong; 2010.

19. Widyarini A. Efektivitas Penyuluhan Menstruasi terhadap Tingkat Kecemasan menghadapi Menarche pada Siswi Usia 9-11 Tahun di SDTI Ibnu Abbas Yogyakarta. Poltekkes Kebidanan Yogyakarta; 2011.

20. Isnaini. Perbedaan Tingkat Kecemasan terhadap Menarche Sebelum dan Sesudah diberikan Penyuluhan tentang Mestruasi pada Siswi Kelas 5 Dan 6 di SD Negri Ngoto Bantul. STIKES Alma Ata Yogyakarta; 2011.

21. Yulia AP. Hubungan Pengetahuan dengan Tingkat Kecemasan Siswi dalam Menghadapi Menarche di Sd Negeri 03 Alai Padang. e-Skripsi Universitas Andalas. Universitas Andalas; 2015. 